\section{Measurement of Creep in Keratin Fibres}

Creer characteristics of wool fibres in water have yielded valuable information on the fine structure of keratin ${ }^{1-4}$. Creep fluidity at high extensions is also of technological significance ${ }^{5}$.

The absence of plastic flow in unmodified fibres (as made evident by the perfect reversibility of extensions greater than 70 per cent) and knowledge of the $\alpha-\beta$ transformation has led to the use of constant loads throughout creep tests on the assumption that the load per molecular chain remains constant. Even under these conditions variations among fibres drawn from the same staple are large with respect to initial extension and rate of creep ${ }^{6}$.

We have noted that the occurrence of the wellknown stages of the load-extension curve are relatively constant with respect to extension but extremely variable with respect to stress. Stress at 30 per cent extension varies between 4 and $7 \mathrm{kgm} . / \mathrm{mm} .{ }^{2}$; two typical examples are set out in Table 1.

Table 1. Stress of Wool Fibres at 30 Per Cent Extension ( $S 30$ )

$\begin{array}{ccc}\text { Fibre } & \text { Sample } A & \\ \text { Diameter } & \\ \text { No. } & (\mu) & S 30 \\ 1 & 22 \cdot 4 & 4 \cdot 60 \\ 2 & 24 \cdot 7 & 4 \cdot 62 \\ 3 & 26 \cdot 0 & 4 \cdot 51 \\ 4 & 21 \cdot 8 & 4 \cdot 75 \\ 5 & 19 \cdot 2 & 5 \cdot 88 \\ 6 & 20 \cdot 3 & \mathbf{4} \cdot 65 \\ 7 & 22 \cdot 4 & 5 \cdot 36 \\ 8 & 21 \cdot 3 & 4 \cdot 69\end{array}$

$\begin{array}{cc}\text { Fibre } & \begin{array}{c}\text { Sample } B \\ \text { Diameter } \\ \text { No. }\end{array} \\ 1 & (\mu) \\ 1 & 18 \cdot 2 \\ 2 & 21 \cdot 4 \\ 3 & 23 \cdot 8 \\ 4 & 21 \cdot 0 \\ 5 & 20 \cdot 2 \\ 6 & 21 \cdot 4 \\ 7 & 20 \cdot 1 \\ 8 & 19 \cdot 2\end{array}$

$S 30$
$6 \cdot 13$
$5 \cdot 58$
$5 \cdot 78$
$5 \cdot 98$
$6 \cdot 31$
$6 \cdot 06$
$6 \cdot 44$
$6 \cdot 02$

The application of a constant stress of $6 \mathrm{kgm}$./ $\mathrm{mm} .^{2}$ would result in an initial extension of 30 50 per cent for sample $A$ fibres, whereas sample $B$ fibres would give initial extensions of $c .30$ per cent. A comparison of these two samples would not involve creep at the same level of extension.

It is well known that extension to 30 per cent under specified conditions does not damage wool fibres $^{7}$ and by calibrating a fibre in this way it is possible to estimate, with reasonable accuracy, the load required to give any extension. Details of an experiment comparing this technique with the con. stant stress method are given in Table 2.

\begin{tabular}{|c|c|c|c|c|}
\hline \multirow[b]{2}{*}{ Group } & \multicolumn{3}{|c|}{ Table 2} & \multirow{2}{*}{$\begin{array}{c}\text { Stress } \\
\text { applied as a } \\
\text { percentage } \\
\text { of } S 30\end{array}$} \\
\hline & $\begin{array}{l}\text { Fibre } \\
\text { No. }\end{array}$ & $\begin{array}{c}S 30 \\
\text { kgm. mm. }{ }^{2}\end{array}$ & $\begin{array}{l}\text { Stress applied } \\
\text { kgm. mm. }\end{array}$ & \\
\hline 1 & $\begin{array}{l}1 \\
2 \\
3 \\
4\end{array}$ & $\begin{array}{l}\mathbf{5} \cdot \mathbf{5 4} \\
\mathbf{5} \cdot 75 \\
\mathbf{6} \cdot 14 \\
\mathbf{5} \cdot \mathbf{5 7}\end{array}$ & $\begin{array}{r}3 \cdot 88 \\
4 \cdot 03 \\
4 \cdot 30 \\
3 \cdot 90 \\
\text { mean } 4 \cdot 03\end{array}$ & $\begin{array}{l}70 \\
70 \\
70 \\
70\end{array}$ \\
\hline 2 & $\begin{array}{l}5 \\
6 \\
7 \\
8\end{array}$ & $\begin{array}{l}5 \cdot 01 \\
5 \cdot 47 \\
5 \cdot 77 \\
4 \cdot 68\end{array}$ & $\begin{array}{r}4 \cdot 03 \\
4 \cdot 03 \\
4 \cdot 03 \\
4 \cdot 03 \\
\text { mean } 4 \cdot 03\end{array}$ & $\begin{array}{l}80 \cdot 4 \\
73 \cdot 7 \\
69 \cdot 8 \\
86 \cdot 1\end{array}$ \\
\hline
\end{tabular}

Both groups (drawn from the same staple) have the same mean stress applied. Group 1 fibres have variable stresses but each stress represents a constant fraction of $S 30$, whereas Group 2 fibres have constant stresses bearing no relation to $S 30$. The creep curves of these fibres in distilled water at $15.4^{\circ} \mathrm{C}$. is illustrated in Fig. 1.

The great reduction in variation of fibres in Group 1 indicates the value of the technique in experiments requiring the comparison of creep properties at a definite extension. We have used the method with equal success in the post-yield region. for example, by using stresses of 130 per cent $S 30$. It appears that investigations of load-extension of fibres to the

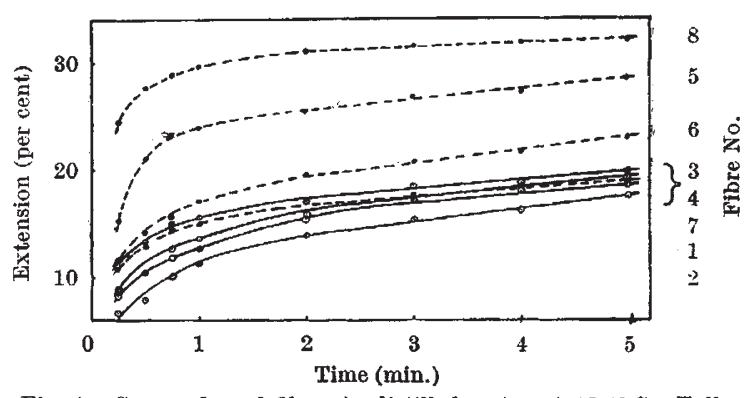

Fig. 1. Creep of wool fibres in distilled water at $15 \cdot 4^{\circ} \mathrm{C}$. Full lines, flbres under stress equal to 70 per cent $S 30 ;$ broken line,
fibres under mean stress of $4.03 \mathrm{kgm} . / \mathrm{mm}^{2}{ }^{2}$

breaking point will enable accurate prediction of creep properties at any given load in unmodified keratin fibres.

\section{E. Balasubramaniam}

K. J. WHITELEY

School of Wool Technology,

University of New South Wales,

Sydney.

${ }^{1}$ Speakman, J. B., Nature, 159, 338 (1947).

${ }^{2}$ Ripa, O., and Speakman, J. B., Text. Res. J., 21, 210 (1951).

s Feughelman, M., J. Text. Inst., 45, T630 (1954).

${ }^{4}$ Peters, I., Proc. Intern. Wool Text. Res. Conf. A ustral., D 76 (1955).

"Whiteley, K. J., and Speakman, J. B., Text. Res. J., 30, 46 (1960).

Burley, R. W., and Speakman, J. B., Text. Res, J., 23, 702 (1953).

'Speakman, J. B., J. Text. Inst., 38, T 102 (1947).

\section{BIOCHEMISTRY}

\section{Identification of Sugars in Royal Jelly}

THE presence of sugars in the nutrients of the honeybee termed royal jelly has been reported; but the analyses were based on fermentation and reducing power investigations ${ }^{1,2}$ or paper chromatography evidence ${ }^{3,4}$. The chromatographic evidence indicated the presence of components having the same $R_{F}$ values as glucose and sucrose in all samples studied, and in certain samples, $R_{F}$ values corresponding to sucrose, maltose and ribose. Because this evidence was not based on an evaluation of physical constants of the crystalline sugars and their derivatives, an investigation was undertaken to isolate and identify precisely the carbohydrate components of this bee larval food.

A fresh quantity of royal jelly (100 gm.) (kindly supplied by R. B. Wilson, Inc., 250 Park Avenue, New York, 17) was placed in casing and dialysed in water at $5^{\circ} \mathrm{C}$. with frequent changing of this solvent, until the dialysate showed a negative Molisch test. This required 20 days and about 5 litres of water. The dialysate was concentrated (in vacuo) at $40^{\circ} \mathrm{C}$. to a thin syrup and the residual water removed by adding increments of dry ethanol and evaporating the ethanol-water azeotrope under vacuum. Ass the water was removed, the syrup hardened into a plastic solid which, after complete dehydration, was then transferred with $100 \mathrm{ml}$. of ethanol to a Waring blender. During the homogenization process which followed, requiring 15 days, a total of 5 litres of dry ethanol, added in $150 \mathrm{ml}$. increments, was used for extracting the sugars from the amorphous product. Approximately 15 per cent of the dialytic substance was insoluble in ethanol and may be principally the pteridin compound which has been reported ${ }^{5}$.

The alcohol-soluble components, principally sugars, were concentrated (in vacuo) at $40^{\circ} \mathrm{C}$. to a thin syrup 